\title{
Musculoskeletal medicine: an Austrian perspective part 1
}

\author{
Richard Crevenna · Franz Kainberger
}

From the viewpoint of multidisciplinary and interdisciplinary healthcare and associated with demographic change, musculoskeletal medicine seems to be one of the most important challenges now and in the future [1]. Musculoskeletal medicine means diagnosis and treatment of musculoskeletal disorders (such as injuries and diseases), namely problems and dysfunctions arising from the musculoskeletal system, which includes bones and joints of the limbs, spine and muscles. Musculoskeletal problems are responsible for a very large part of consultations of general practitioners. After this, many different medical specialities are involved. Therefore, problems with the musculoskeletal system have an enormous impact on health services with high clinical and socioeconomic relevance [1].

This first of two musculoskeletal issues of the Wiener klinische Wochenschrift aims to give a short overview about (more conservative) aspects of musculoskeletal medicine and four Austrian expert groups have therefore been invited to give an insight into their work. In this issue, you can find specific information about health outcomes and current and future concept trends in outcomes research in low back pain, a novel online exercise program for people suffering from hemophilia, and a practical concept concerning exercise and physical therapy for patients

Univ. Prof. Dr. R. Crevenna, MBA, MMSc ( $₫)$ Department of Physical Medicine, Rehabilitation and Occupational Medicine, Medical University of Vienna, Waehringer Guertel 18-20, 1090 Vienna, Austria richard.crevenna@meduniwien.ac.at

\section{F. Kainberger}

Division of Neuro- and Musculoskeletal Radiology, Department of Biomedical Imaging and Image-Guided Therapy, Medical University of Vienna, Vienna, Austria suffering from metastatic bone disease or multiple myeloma.

For patients suffering from low back pain, Grabovac and Dorner report a reduction in activities of daily living, in working ability, and in sexual function to be the most important health outcomes in the subjective perception [2]. They recommend a multidisciplinary approach which includes multiprofessional care teams, participation of the patients, and involvement of different settings, such as workplace, home, and physical training facilities [2]. Stamm et al. provide an overview and discuss current concepts and future trends in outcomes research in non-specific low back pain and indicate that active patient involvement seems to be an essential part of nonpharmacological treatment in low back pain which should be considered in terms of outcomes and outcome measurement [3]. Wagner et al. present a novel online exercise program for people suffering from hemophilia, which is very easily accessible. This online exercise program is designed for patients who have limited access to training for a regular home-based training to benefit from increased physical fitness and joint stability [4]. Keilani et al. present a practical concept focusing on typical aspects of regular exercise and physical therapy for patients suffering from metastatic bone disease or multiple myeloma. The authors mention typical contraindications and considerations to ensure the safety and effectiveness in these patient groups [5].

In this first musculoskeletal issue, we would like to give you an insight into these specific aspects of musculoskeletal medicine which are presented in a comprehensive way. We therefore would like to thank Wiener klinische Wochenschrift for the kind invitation to edit two issues with this important main topic. Thanks to all authors and reviewers who made this edition possible. 


\section{editorial}

Conflict of interest R. Crevenna and F. Kainberger declare that they have no competing interests.

\section{References}

1. Windhager R. Increase of musculoskeletal pain in Austria-what are we waiting for? Wien Klin Wochenschr. 2006;118(3-4):67-8.

2. Grabovac I, Dorner TE. Association between low back pain and various everyday performances: activities of daily living, ability to work and sexual function. Wien Klin Wochenschr. 2019; https://doi.org/10.1007/s00508-01901542-7.

3. Stamm TA, Boesendorfer A, Omara M, Ritschl V, Štefanac S, Mosor E. Outcomes research in non-specific low back pain: knowledge transfer in clinical practice. Wien Klin Wochenschr. 2019; https://doi.org/10.1007/s00508-0191523-4.

4. Wagner B, Seuser A, Krüger S, Herzig ML, Hilberg T, Ay C, et al. Establishing an online physical exercise program for people with hemophilia. Wien Klin Wochenschr. 2019; https://doi.org/10.1007/s00508-019-01548-1.

5. Keilani M, Kainberger F, Pataraia A, Hasenöhrl T, Wagner B, PalmaS, et al. Typical aspects in the rehabilitation of cancer patients suffering from metastatic bone disease or multiple myeloma. Wien Klin Wochenschr. 2019; https://doi.org/ 10.1007/s00508-019-1524-3.

Publisher's Note Springer Nature remains neutral with regard to jurisdictional claims in published maps and institutional affiliations. 